Grand Valley State University

ScholarWorks@GVSU

\title{
Acute Renal Failure Requiring Renal Replacement Therapy in the Intensive Care Unit: Impact on Prognostic Assessment for Shared Decision-Making
}

Robert F. Johnson Jr.

Grand Valley State University

Jillian Gustin

The Ohio State University

Follow this and additional works at: https://scholarworks.gvsu.edu/kcon_articles

Part of the Analytical, Diagnostic and Therapeutic Techniques and Equipment Commons, and the Bioethics and Medical Ethics Commons

\section{ScholarWorks Citation}

Johnson, Robert F. Jr. and Gustin, Jillian, "Acute Renal Failure Requiring Renal Replacement Therapy in the Intensive Care Unit: Impact on Prognostic Assessment for Shared Decision-Making" (2011). Peer Reviewed Articles. 49.

https://scholarworks.gvsu.edu/kcon_articles/49

This Article is brought to you for free and open access by the Kirkhof College of Nursing at ScholarWorks@GVSU. It has been accepted for inclusion in Peer Reviewed Articles by an authorized administrator of ScholarWorks@GVSU.

For more information, please contact scholarworks@gvsu.edu. 
ACUTE RENAL FAILURE REQUIRING RENAL REPLACEMENT THERAPY IN THE INTENSIVE CARE UNIT: IMPACT ON PROGNOSTIC ASSESSMENT FOR SHARED DECISION-MAKING

Case Scenario and Literature Review

Robert F. Johnson Jr., M.D. and Jillian Gustin, M.D. Center for Palliative Care

The Ohio State University Medical Center

Columbus, Ohio

Corresponding Author and Request for Reprints:

Robert F. Johnson Jr., M.D.

Center for Palliative Care

The Ohio State University Medical Center

453 West $10^{\text {th }}$ Avenue

Columbus, $\mathrm{OH} 43210$

E-mail: robert.johnson@osumc.edu

Telephone: 614 366-8726

Sources of support and conflicts of interest: None

Running Head: Acute Renal Failure in the Intensive Care Unit 


\section{Abstract}

A 69 year-old female was receiving renal replacement therapy (RRT) for acute renal failure (ARF) in an intensive care unit (ICU). Consultation was requested from the palliative medicine service to facilitate a shared decision-making process regarding goals of care.

Clinician responsibility in shared decision-making includes the formulation and expression of a prognostic assessment providing the necessary perspective for a spokesperson to match patient values with treatment options. For this patient, ARF requiring RRT in the ICU was used as a focal point for preparing a prognostic assessment. A prognostic assessment should include the outcomes of most importance to a discussion of goals of care: mortality risk and survivor functional status, in this case including renal recovery. A systematic review of the literature was conducted to document published data regarding these outcomes for adult patients receiving RRT for ARF in the ICU. 41 studies met the inclusion criteria. The combined mean values for short-term mortality, long-term mortality, renal-function recovery of short- term survivors, and renal-function recovery of long-term survivors were $51.7 \%, 68.6 \%, 82.0 \%$, and $88.4 \%$ respectively.

This case example illustrates a process for formulating and expressing a prognostic assessment for an ICU patient requiring RRT for ARF. Data from the literature review provides baseline information that requires adjustment to reflect specific patient circumstances. The nature of the acute primary process, comorbidities, and severity of illness are key modifiers. Finally, the prognostic assessment is expressed during a family meeting using recommended principles of communication. 


\section{Case Scenario}

B.W., a 69-year-old female with a past medical history including hypertension, diabetes mellitus, and surgical treatment for obesity was evaluated by the palliative medicine service on the sixth day after admission to the intensive care unit (ICU). She had presented with an acute ST-segment elevation myocardial infarction and was now receiving mechanical ventilation for cardiogenic pulmonary edema and suspected aspiration pneumonitis as well as multiple vasoactive medication infusions to maintain adequate blood pressure. Continuous venovenous hemodiafiltration (CVVHD) was initiated on the fourth hospital day because of anuria and a progressive increase in serum creatinine. The patient was being medicated intermittently for confusion and agitation. A non-contrast CT scan of the brain, hematolgic indices, and serum bilirubin were normal.

Initial discussion with the patient's husband, her designated surrogate decision-maker, indicated a primary concern with the possibility of chronic dialysis. "She would never want that." The Palliative Care team considered how best to address this concern and provide an accurate prognosis regarding the need for chronic dialysis given her current clinical condition. 


\section{Introduction}

Acute renal failure (ARF) is a common occurrence in patients likely to die in the ICU.1,2 ARF requiring renal replacement therapy (RRT) has been correlated with a significantly increased mortality risk in critically ill ICU patients in a variety of clinical categories. ${ }^{3-5}$ As such, ARF requiring RRT can provide a focal point for prognostic assessment by clinicians for this high-risk group of ICU patients. For the family described in the case scenario, and many others, RRT represents an important patient values and quality-of-life variable. ${ }^{6}$ The presence of ongoing RRT, its imminent need, or likely possibility can prompt a discussion of the goals and plans for management, including decisions to forego life-sustaining interventions. Palliative care is often consulted to help families consider goals of care in this setting. However, there is little written about how best to prognosticate on the need for long-term RRT in critically-ill patients as one important factor in goals of care discussions. This paper will help to address this absence in the literature.

As Palliative Care providers, we know that shared decision-making is the preferred model for interacting with families of incapacitated critically ill patients. ${ }^{7,8}$ A key component of our responsibility in the shared decision-making process is to prognosticate - to effectively communicate information about the expectations for positive or negative outcomes with different management goals and plans. ${ }^{9}$ Prognostic assessment by the clinical team is essential in enabling the family to frame their decisions in the context of patient values. Prognostication and shared decision-making in this setting is extremely challenging. The medical information that we provide based on a review of the literature should be counterbalanced by the inherent uncertainty of predicting the course of events for a given patient situation. Moreover, an estimate of mortality risk needs to be combined with a discussion of the projected functional and quality of life implications of the acute illness IF short term survival is achieved. Oftentimes, it is difficult to predict long-term outcomes such as the need for RRT when the short-term outcome is so uncertain.

To describe the process of formulating and expressing a prognostic assessment for the patient described in the introductory scenario, ARF requiring RRT in the ICU will be used as a 
central feature of the patient's condition to focus the necessary research and analysis. A sequence of three steps for the formulation and expression of a prognostic assessment will be discussed in this paper. First, we will provide a literature review of outcomes most relevant to family decision-makers. Second, we will incorporate this data with other clinical variables to arrive at a meaningful prognostic assessment for this individual patient. Finally, we will recommend an approach to communicate this prognostic assessment in an understandable and accurate manner that fosters shared decision-making with the family. ${ }^{10}$ 


\section{Literature Review: Outcome of Acute Renal Failure requiring Renal Replacement Therapy in the Intensive Care Unit \\ Methods}

We systematically searched the literature for articles published between January 1, 2000 and June 1, 2010 providing absolute number data on mortality and renal recovery of patients receiving RRT for ARF in the ICU. The search was initiated in PubMed using MeSH terms "Acute Renal Failure" or "Acute Kidney Failure" and "Renal Replacement Therapy" or "Renal Dialysis" and "Intensive Care Units" or "Critical IIIness" and "Outcome Assessment (Health Care)" or "Epidemiology." Additional electronic databases (Ovid/Medline and EMBASE) were searched using keywords acute renal failure, acute kidney injury, renal replacement therapy, dialysis, critical illness, and intensive care units. Also searched were the websites of major journals likely to publish articles relevant to our topic: Critical Care Medicine; Intensive Care Medicine; American Journal of Respiratory and Critical Care Medicine; Journal of the American Society of Nephrology; Nephrology, Dialysis, and Transplantation; and American Journal of Kidney Diseases. In addition, bibliographies of papers that potentially met our criteria were reviewed for further references.

Studies published in English between 2000 and 2010 were included in this analysis if they met the following criteria: (1) patients greater than 18 years old, (2) patients received renal replacement therapy for acute renal failure in an intensive care unit, (3) outcome reported as mortality and recovery or not of renal function defined as independence or not from renal replacement therapy at a specified time interval or intervals starting with the intensive care unit stay, (4) patients with identified pre-existing renal dysfunction excluded, (5) patients with heart, liver, lung, or kidney transplants not included.

\section{Results}

41 articles meeting the inclusion criteria were identified (Table 1). 25 studies reported short-term (ICU discharge, hospital discharge, or up to 30 days) outcome on a total of 4765 patients. Mean short-term mortality was $54.8 \% .83 \%$ of the short-term survivors were no longer receiving renal replacement therapy. 9 papers provided long-term outcome data on 4797 
patients. A mean of $62.1 \%$ of these patients died during long-term follow-up ranging from 3 months to 5 years after hospital discharge. At the time of data collection a mean of $91.5 \%$ of the survivors in these long-term reports were not receiving renal replacement therapy. Finally, 7 studies reported both short- and long-term outcome in the same group of patients. In the combined 2290 patients reported in these papers, the mean values for short-term mortality, longterm mortality, renal-function recovery of short- term survivors, and renal-function recovery of long-term survivors were $45.8 \%, 51.8 \%, 86.8 \%$, and $94.3 \%$ respectively.

In the 32 studies reporting short-term mortality, the median value was $51.1 \%$ with an upper quartile of $60.3 \%$ to $80.6 \%$. 16 of the studies reported long-term mortality. The median mortality in these investigations was $67.9 \%$ with an upper quartile of $85.3 \%$ to $87.7 \%$. The mean long-term follow-up interval was 15.7 months and median 6 months. 


\section{Formulating the Prognostic Assessment}

Formulating a prognostic assessment for the patient in the introductory case scenario to aid in shared decision-making begins with the summary statistics from the literature review. However, prognostication for this patient becomes more challenging when her specific circumstances are reviewed. The primary acute diagnosis and the severity and extent of important comorbid conditions influence short- and long-term mortality and determine the functional status and quality of life of survivors. ${ }^{51}$ Severity of the acute illness as assessed by the extent of organs systems dysfunction is the primary determinant of short-term mortality. ${ }^{52} \mathrm{~A}$ general principle is that, with the exception of some patients in the ICU after planned surgical procedures, the functional status and quality of life for ICU survivors will not exceed their premorbid condition. ${ }^{53}$ In all likelihood, the health-related status will be worse.

The patient presented in the introductory case scenario was receiving RRT for ARF in the ICU. Based on this information alone the estimated short- and long-term mortalities would be $50 \%$ and $60 \%$ respectively. $90 \%$ of survivors would be expected to be free of long-term RRT. However, she presented with a primary diagnosis of acute myocardial infarction and had multiple subsequent complications including, but not limited to, ARF. Whether the patient could recover to the point where additional interventions to retrieve myocardial function and reduce short- and long-term mortality risk of this serious primary process was doubtful. Short-term survival would likely be associated with health-related functional and quality of life limitations related to heart failure. Sepsis related to aspiration pneumonitis was an acute comorbid event predicted to negatively affect outcomes ${ }^{54}$ in addition to the risk associated with delirium. ${ }^{55}$ Overt failure of the circulatory, respiratory, and renal organ-systems function identified a high severity of illness, justifying a modification of the short-term mortality estimate to the higher frequencies of those reported in the literature review. ${ }^{56}$ Moreover, she had significant chronic comorbid conditions such as hypertension, diabetes mellitus, and obesity that were likely to adversely influence the short-term and, to a greater extent, long-term mortality as well as survivor function and quality of life. Finally, age is a necessary but not primary consideration in discussions for decision-making 
in the ICU. The scenario patient was in an age group associated with higher risk of adverse outcomes. $^{57}$

The preceding analysis of patient-specific factors (acute disease process, comorbidities, and severity of illness) leads to a revision of original estimates based on the starting point of the risks faced by any patient receiving RRT for ARF in the ICU. For the purpose of formulating a prognostic assessment regarding the scenario patient, the short- and long-term mortality estimates would be $75-80 \%$ and $85-90 \%$ respectively. Short- or long-term survival would have a relatively low likelihood of requiring chronic RRT. However, because of the previously mentioned acute and preexisting comorbidities other health-related limitations of function and quality of life would be anticipated. The most optimistic outcome prediction of returning home with some independent function would include significant time and resource investments for convalescence and rehabilitation. These would be necessary to bridge immediate post ICU survival to the possible resumption of an independent existence outside of an institutional setting. 


\section{Communicating the Prognostic Assessment}

Palliative Care clinicians are often asked to help communicate prognostic information in a way that will foster shared decision-making with families of critically ill patients. The challenge of these types of discussions is providing accurate prognostic information in the context of medical uncertainty. How should we express the likely outcomes for a patient like Mrs. W when the prognosis is affected by a multiple factors associated with that individual's clinical case? How should we respond to her husband's statement about long-term RRT when the RRT is just a small part of the prognostic picture?

We know that most families of incapacitated ICU patients wish to receive prognostic estimates about the condition of their loved one. ${ }^{58}$ Moreover, avoiding a straightforward discussion of prognosis with family members of an incapacitated ICU patient because of uncertainty about the prognosis or concern for extinguishing hope is misguided. ${ }^{59}$ Prognostic information allows the designated surrogate decision-maker and other family members to participate in shared decision-making and help them prepare emotionally and logistically for a fatal or significantly adverse outcome.60 In addition, a carefully considered and communicated prognostic assessment assists the family in reframing the concept of hope while dealing with a life-threatening illness. ${ }^{61}$ It has been demonstrated that family members generally recognize the inherent uncertainty of medical predictions while still highly valuing discussions about prognosis. ${ }^{62}$

Although a discussion of how to conduct effective family meetings to foster shared decision-making is beyond the scope of this paper, certain specific strategies can be recommended for delivering the prognostic assessment within a broader conversation regarding patient and family values and goals. Initial discussions with Mr. W should assess his understanding of his wife's illness including her prognosis as well as address the type of information he wishes to receive, in what form, and important components of medical decisionmaking for him. ${ }^{7}$ His prognostic understanding will likely come from many sources, not just medical input from physicians. ${ }^{63}$ Exploration of his comment "She would not want that" is warranted to further understand his distress and its impact on future medical decisions. 
shot", sets a tone for the subsequent discussion regarding prognosis: ${ }^{64}$

....." All of the people caring for Mrs. W are doing their best to improve her condition. However, she is not responding as we would hope and remains critically ill. This means that she is at significant risk of dying despite our best efforts to save her".....

If, during prior discussions, Mr. W was inclined toward numeric probabilities as a means to consider his wife's possible illness trajectories, expressions of mortality risk are recommended but should be expressed as natural frequencies and framed as outcomes for populations rather than individuals: 65

....."Unfortunately I cannot predict for you exactly what is going to happen. I will give you the best prediction I can based on prior studies and our own experience and judgment. If we were to look at 100 people in Mrs. W's condition about 75-80 of them would not survive to leave the hospital. Of the people who survived, more would predictably die within 1-2 years; by that time about 90 of the original 100 would be dead. .......to address the concern you mentioned yesterday, Mr. W, only 2 or 3 out of 10 - of those able to survive - would need to be on dialysis long-term"..... Incorporating the possibility of short-term survival, predictions regarding functional outcomes such as health-related quality of life, need for ongoing life support measures, and disposition locations should be included in addition to an acknowledgement of the uncertain outcome: 58

.... "If she survives, her heart would be weakened and this - along with her other health problems before this one - would cause limits to her ability to function and enjoy life. I would anticipate the need for a significant period of time in a nursing home to receive 24 hour care. There is no way at the present time to know what the result of this would be but it is highly unlikely that she will return home like she was before"..... 


\section{Conclusion}

A shared decision-making process offers the best opportunity to respect patient autonomy while optimizing medical care for incapacitated ICU patients. Family meetings provide a forum for this process to occur. It is the responsibility of the healthcare provider facilitating a family meeting to provide a well formulated and effectively communicated prognostic assessment.

There are limitations to the application of the literature review reported here to formulating a prognostic assessment. The studies analyzed present data from a heterogeneous group of patients receiving different forms of RRT. This allows the accumulation of a sizeable sample and a statement of a general outcome trend with some confidence but limits the ability to accurately predict outcome for an individual patient. Many of the studies in the literature review reported data from the experimental groups in controlled investigations of issues such as the timing, technique, and technology of the administration of RRT. These issues are of great importance in promoting the best possible outcomes for ARF patients receiving RRT. However, current reviews of this topic do not indicate an ability to predict a better or worse outcome based on specific factors such as timing, intensity or mode of RRT. ${ }^{2}$ The majority of patients in ICUs at the present time will be receiving a continuous RRT technique with a biocompatible membrane. ${ }^{66}$ For the purpose of formulating and expressing a prognostic assessment as part of shared decision-making for an incapacitated ICU patient the data presented in the preceding literature review represents a baseline that must be integrated with other patient-specific considerations.

Acute renal failure (ARF) requiring renal replacement therapy (RRT) provides a focal point for developing a prognostic assessment for a critically ill patient with multiple organ-system failure. Combining historical data from a literature review with clinical judgment regarding the effects on outcome of comorbidities and severity of acute illness is recommended as an approach to formulating the prognostic assessment. Attention to key principles of communication in shared decision-making enables effective expression of the prognostic assessment to the family. 
Acute Renal Failure in the Intensive Care Unit

\section{Author Disclosure Statement}

No conflicting financial interests exist. 


\section{References}

1. Uchino S, Kellum JA, Bellomo R, Doig GS, Morimatsu H, Morgera S, Schetz M, Tan I, Bouman C, Macedo E, Gibney N, Tolwani A, Ronco C, for the Beginning and Ending Supportive Therapy for the Kidney (BEST Kidney) Investigators: Acute renal failure in critically ill patients: a multinational, multicenter study. JAMA 2005;294:813-818.

2. Pannu N, Klarenbach S, Wiebe N, Manns B, Tonelli M: Renal replacement therapy in patients with acute renal failure, a systematic review. JAMA 2008;299:793-805.

3. Coca SG, Yusuf B, Schlipak MG, Garg AX, Parikh CR: Long-term risk of mortality and other adverse outcomes after acute kidney injury: a systematic review and meta-analysis. Am J Kidney Dis 2009;53:961-973.

4. Hoste EA, Kellum JA, Katz NM, Rosner MH, Haase M, Ronco C: Epidemiology of acute kidney injury. Contrib Nephrol 2010;165:1-8.

5. Schiffl H, Fischer R: Five-year outcomes of severe acute kidney injury requiring renal replacement therapy. Nephrol Dial Transplant 2008;23:2235-2241.

6. Morton RL, Devitt J, Howard K, Anderson K, Snelling P, Cass A: Patient views about treatment of stage 5 CKD: a qualitative analysis of semistructured interviews. Am J Kidney Dis 2010;55:431-440.

7. Davidson JE, Powers K, Hedayat KM, Tieszen M, Kon AA, Shepard E, Spuhler V, Todres ID, Levy M, Barr J, Ghandi R, Hirsch G, Armstrong D: Clinical practice guidelines for support of the family in the patient-centered intensive care unit: American College of Critical Care Medicine Task Force 2004-2005. Crit Care Med 2007;35:605-622.

8. Truog RD, Campbell ML, Curtis JR, Haas CE, Luce JM, Rubenfeld GD, Rushton CH, Kaufman, DC: Recommendations for end-of-life care in the intensive care unit: A consensus statement by the American Academy of Critical Care Medicine. Crit Care Med 2008;36:953-963.

9. Schaefer KG, Block SD: Physician communication with families in the ICU: evidencebased strategies for improvement. Curr Opin Crit Care 2009;15:569-577. 
10. Lamont EB, Christakis NA: Some elements of prognosis in terminal cancer. Oncology 1999;13:1165-170.

11. Albright RC, Smelser JM, McCarthy JT, Homburger HA, Bergstralh EJ, Larson TS:

Patient survival and renal recovery in acute renal failure. Mayo Clin Proc 2000;75:11411147.

12. Cole L, Bellomo R, Silvester Reeves J: A prospective, multicenter study of the epidemiology, management, and outcome of severe acute renal failure in a "closed" ICU system. Am J Respir Crit Care Med 2000;162:191-196.

13. Ronco C, Bellomo R, Homel P, Brendolan A Dan M, Piccini P, LaGreca G: Effects of different doses in continuous veno-venous haemofiltration on outcomes of acute renal failure. Lancet 2000;356:26-30.

14. Daxi Jl, Gong D, Honglang X, Bin X, Yun L, Leishi L: A retrospective study of continuous renal replacement therapy versus intermittent hemodialysis in severe acute renal failure. Chin Med J 2001;114:1157-1161.

15. Mehta RL, McDonald B, Gabbai FB, Pahl M, Pasqual MT, Farkas A, Kaplan RM: A randomized clinical trial of continuous versus intermittent dialysis for acute renal failure. Kidney Int 2001;60:1154-1163.

16. Noble JS, MacKirdy FN, Donaldson SI, Howie JC: Renal and respiratory failure in Scottish ICUs. Anaesthesia 2001;56:124-129.

17. Ponikvar JB, Rus RR, Kenda RB, Bren AF, Ponikvar RR: Low-flux versus high-flux synthetic dialysis membrane in acute renal failure: prospective randomized study. Int $\mathrm{J}$ Artif Organs 2001;25:946-950.

18. Bouman CSC, Oudermans-van Straaten HM, Tijsen JGP, Zandstra D, Kesecioglu J: Effects of early high-volume continuous hemofiltration on survival and recovery of renal function in intensive care units with acute renal failure. Crit Care Med 2002;30:22052211.

19. Schiffl H, Lang SM, Fischer R: Daily hemodialysis and the outcome of acute renal failure. N Engl J Med 2002;346:305-310. 
20. Manns B, Doig CJ, Lee H, Dean S, Tonelli M, Johnson D, Donaldson C: Cost of acute renal failure requiring dialysis in the intensive care unit: Clinical and resource implications of renal recovery. Crit Care Med 2003;31:449-455.

21. Augustine JJ, Sandy D, Seifert TH, Paganini EP: A randomized controlled trial comparing intermittent with continuous dialysis in patients with acute renal failure. Am J Kidney Dis 2004;44(6):1000-1007.

22. Berghmans T, Meert AP, Markiewicz E, Sculier JP: Continuous venovenous haemofiltration in cancer patients with renal failure: a single centre experience. Support Care Cancer 2004;12:306-311.

23. Chang JW, Yang WS, Seo JW, Lee JS, Lee SK, Park SK: Continuous venovenous hemodiafiltration versus hemodialysis as renal replacement therapy in patients with acute renal failure in the intensive care unit. Scand J Urol Nephrol 2004;38:417-421.

24. Jacka MJ, Ivancinova X, Gibney N: Continuous renal replacement therapy improves renal recovery from acute renal failure. Can J Anesth 2005;52:327-332.

25. Luckraz H, Gravenor MB, George R, Taylor S, Williams A, Ashraf S, Argano V, Youhana A: Long and short-term outcomes in patients requiring continuous renal replacement therapy after cardiopulmonary bypass. Eur J Cardiothorac Surg 2005;27:906-909.

26. Uehlinger DE, Jakob SM, Ferrari P, Eichelberger M, Uyen HD, Marti HP, Mohaupt MG, Vogt B, Rothen HU, Regli B, Takala J, Frey FJ: Comparison of continuous and intermittent renal replacement therapy for acute renal failure. Nephrol Dial Transplant 2005;20:1630-1637.

27. Waldrop J, Ciraulo DL, Milner TP, Gregori D, Kendrick AS, Richart CM, Maxwell RA, Barker DE: A comparison of continuous renal replacment therapy to intermittent dialysis in the management of renal insufficiency in the acutely ill surgical patient. Am Surg 2005;71:36-39.

28. Tolwani AJ, Campbell RC, Stofan BS, Lai R, Oster RA, Wille KM: Standard versus highdose CVVHDF for ICU-related acute renal failure. J Am Soc Nephrol 2008;19:1233-1238. 
29. Faulhaber-Walter R, Hafer C, Jahr N, Vahlbruch J, Hoy L, Haller H, Fliser D, Kielstein JT: The Hannover dialysis outcome study: comparison of standard versus intensified extended dialyisi for treatment of patients with acute kidney injury in the intensive care unit. Nephrol Dial Transplant 2009;24:2179-2186.

30. Hussain S, Piering W, Mohyuddin T, Saleh M, Zhu YR, Hanan M, Cohen E: Outcome among patients with acute renal failure needing continuous renal replacement therapy: $\mathrm{A}$ single center study. 2009 Hemodial Int;13:205-214.

31. Lins RL, Elseviers MM, Van der Niepen P, Hoste E, Malbrain ML, Damas P, Devriendt J: Intermittent versus continuous renal replacement therapy for acute kidney injury patients admitted to the intensive care unit: results of a randomized clinical trial. Nephrol Dial Transplant 2009;24:512-518.

32. Abe M, Okada K, Suzuki M, Nagura C, Ishihara Y, Fujii Y, Ikeda K, Kaizu K, Matsumoto K: Comparison of sustained hemodiafiltration with continuous venovenous hemodiafiltration for the treatment of critically ill patients with acute kidney injury. Int $\mathrm{J}$ Artif Organs 2010;34:331-338.

33. Franzen D, Rupprecht C, Hauri D, Bleisch JA, Staubli M, Puhan MA: Predicting outcomes in critically ill patients with acute kidney injury undergoing intermittent hemodialysis - a retrospective cohort analysis. Int J Artif Organs 2010;33:15-21.

34. Sood MM, Rigatto C, Zarychanski R, Komenda P, Sood AR, Bueti J, Reslerova M, Roberts D, Mojica J, Kumar A: Acute kidney injury in critically ill patients infected with 2009 pandemic influenza A (H1N1): A report from a Canadian province. Am J Kidney Dis 2010;55:848-855.

35. Morgera S, Kraft AK, Siebert G, Luft FC, Neumayer HH: Long-term outcomes in acute renal failure patients treated with continuous renal replacement therapies. Am J Kidney Dis $2002 ; 40: 275-279$.

36. Bahar I, Akgul A, Ozatik MA, Vural K, Demirbag AE, Boran M, Tasdemir O: Acute renal failure following open heart surgery: Risk factors and prognosis. Perfusion 2005;20:317322. 
37. Landoni G, Zangrillo A, Franco A, Aletti G, Roberti A, Calabro MG, Slaviero G, Bignami E, Marino G: Long-term outcome of patients who require renal replacement therapy after cardiac surgery. Eur J Anaesthesiol 2006;23:17-22.

38. Schiffl H: Renal recovery from acute tubular necrosis requiring renal replacement therapy: A prospective study in critically ill patients. Nephrol Dial Transplant 2006;21:1248-1252.

39. Bell M, Granath F, Schon S, Ekbom A, Martling CR: Continuous renal replacement therapy is associated with less chronic renal failure than intermittent dialysis after acute renal failure. Intensive Care Med 2007;33:773-780.

40. Prescott GJ, Metcalfe W, Baharani J, Khan IH, Simpson K, Smith WCS, MacLeod AM: A prospective national study of acute renal failure treated with RRT: incidence, aetiology, ad outcomes. Nephrol Dial Transplant 2007;2:2513-2519.

41. Fertmann J, Wolf $\mathrm{H}$, Kuchenhoff $\mathrm{H}$, Hofner B, Jauch KW, Hartl WH: Prognostic factors in critically ill surgical patients requiring continuous renal replacement therapy. J Nephrol 2008;21:909-918.

42. Lin YF, Ko WJ, Chu TS, Chen YS, Wu VC, Chen YM: The 90-day mortality and the subsequent renal recovery in critically ill surgical patients requiring acute renal replacement therapy. Am J Surg 2009;198:325-332.

43. Davies RSM, Dawlatly S, Clarkson JR, Bradbury AW, Adam DJ: Outcome in patients requiring renal replacement therapy after open surgical repair for ruptured abdominal aortic aneurysm. Vasc Endivascular Surg 2010;44:170-173.

44. Barratt J, Parajasingam R, Sayers RD, Feehally J: Outcome of acute renal failure following surgical repair of ruptured abdominal aortic aneurysms. Eur J Vasc Endovasc Surg 2000;20:163-168.

45. Korkeila M, Ruokonen E, Takala J: Costs of care, long-term prognosis and quality of life in patients requiring renal replacement therapy during intensive care. Intensive Care Med 2000;26:1824-1831. 
46. Leacche M, Rawn JD, Mihaljevic T, Lin J, Karavas AN, Paul S, Byrne JG: Outcomes in patients with normal serum creatinine and with artificial renal support for acute renal failure developing after coronary artery bypass grafting. Am J Cardiol 2004;93:353-356.

47. Saudan P, Niederberger M, DeSeigneux S, Romand J, Pugin J, Perneger T, Martin PY: Adding a dialysis dose to continuous hemofiltration increases survival in patients with acute renal failure. Kiidney Int 2006;70:1312-1317.

48. Vinsonneau C, Camus C, Combes A, Costa de Beauregard MA, Klouche K, Boulain T, Pallot JL, Chiche JD, Taupin P, Landais P, Dhainaut JF: Continuous venovenous haemodiafiltration versus intermittent haemodialysis for acute renal failure in patients with multiple-organ dysfunction syndrome. Lancet 2006;368:379-385.

49. Darmon M, Thiery G, Ciroldi M, Porcher R, Schlemmer B, Azoulay E: Should dialysis be offered to cancer patients with acute kidney injury? Intensive Care Med 2007;33:765-772.

50. Bellomo R, Cass A, Cole L, Finfer S, Gallagher M, Lo S, McArthur C, McGuiness S, Myburgh J, Norton R, Scheinkestel C, Su S, The RENAL Replacement Therapy Study Investigators: Intensity of continuous renal-replacement therapy in critically ill patients. N Engl J Med 2009;361:1627-1638.

51. Ahlstrom A, Tallgren M, Peltonen S, Rasanen P, Pettila V: Survival and quality of life of patients requiring acute renal replacement therapy. Intensive Care Med 2005;31:12221228.

52. Afessa B, Gajic O, Keegan MT: Severity of illness and organ failure assessment in adult intensive care units. Crit Care Clin 2007;23:639-658.

53. Myhren $\mathrm{H}$, Ekeberg O, Stokland O: Health-related quality of life and return to work after critical illness in general intensive care unit patients: A 1-year follow-up study. Crit Care Med 2010;38:1554-1561.

54. Reynvoet E, Vandijck DM, Blot SI, Dhondt AW, De Waele JJ, Claus S, Buyle FM, Vanholder RC, Hoste EA: Epidemiology of infection in critically ill patients with acute renal failure. Crit Care Med 2009;37:2203-2209. 
55. Maldonado JR: Delerium in the acute care setting: characteristics, diagnosis and treatment. Crit Care Clin 2008;24:657-722.

56. Vincent JL, de Carvalho FB: Severity of illness. Semin Respir Crit Care Med 2010;31:3138.

57. Schmitt R, Coca S, Kanbay M, Tinetti ME, Cantley LG, Parikh CR: Recovery of renal function after acute kidney injury in the elderly: a systematic review and meta-analysis. Am J Kidney Dis 2008;52:262-271.

58. White,DB, Engelberg RA, Wenrich MD, Lo B, Curtis JR: Prognostication during physician-family discussions about limiting life support in intensive care units. Crit Care Med 2007;35:442-448.

59. Leclaire MM, Oakes JM, Weinert CR: Communication of prognostic information for critically ill patients. Chest 2005;128:1728-1735.

60. Apatira L, Boyd EA, Malvar G, Evans LR, Luce JM, Lo B, White DB: Hope, truth and preparing for death: Perspectives of surrogate decision makers. Ann Intern Med 2008;149:861-868.

61. Clayton JM, Hancock K, Parker S, Butow PN, Walder S, Carrick S, Currow D, Ghersi D, Glare P, Hagerty R, Olver IN, Tattersall MHN: Sustaining hope when communicating with terminally patients and their families: a systematic review. Psycho-Oncology 2008;17:641-659.

62. Evans LR, Boyd EA, Malvar G, Apatira L, Luce JM, Lo B, White DB: Surrogate decisionmakers' perspectives on discussing prognosis in the face of uncertainty. Am J Respir Crit Care Med 2009;179:48-53.

63. Boyd EA, Lo B, Evans LR, Malvar G, Apatira L, Luce JM, White DB: "It's not just what the doctor tells me:" Factors that influence surrogate decision-makers perceptions of prognosis. Crit Care Med 2010;38:1270-1275.

64. Treece PD: Communication in the intensive care unit about the end of life. AACN Advanced Critical Care 2007;18:406-414. 
65. Curtis JR, White DB: Practical guidance for evidence-based ICU family conferences. Chest 2008;134:835-843.

66. Uchino S: What is "BEST" RRT practice? Contrib Nephrol 2010;165:244-250. 